\title{
Research on the Conception, Practice and Enlightenment of Global Citizenship Education
}

\author{
Qi Rui \\ School of Marxism, China University of Mining and \\ Technology, \\ Xu Zhou, People's Republic of China \\ E-mail: cherryqi1117@cumt.edu.cn
}

\author{
Zou Fangming* \\ School of Marxism, China University of Mining and \\ Technology, \\ $\mathrm{Xu}$ Zhou, People's Republic of China \\ E-mail: fmzou@cumt.edu.cn
}

\begin{abstract}
This paper aims to make a systematic study of Global Citizenship Education to achieve some experience or enlightenment from it. In particular, the study in this topic has become increasingly meaningful since President Xi Jinping put forward the idea of "promoting the construction of a Community with a Shared Future for Mankind". This paper tells us the concept, goal, content and concrete practices of Global Citizenship Education by means of theoretical analysis and comparative study. The results suggest that, in order to implement the Global Citizenship Education in Chinese colleges and universities, we should pay attention to the following points: setting a national and global aim for this project; providing courses related to Global Citizenship Education which must serve their goals; strengthening cross-cultural exchanges and cooperation in colleges and universities to ensure the Global Citizenship Education can be fully implemented in this process.
\end{abstract}

Keywords-Global Citizenship Education; Theory and Practice; a Community with a Shared Future for Mankind; Enlightenment

\section{INTRODUCTION}

Since the third industrial revolution represented by information technology, the tide of globalization, which is based on the economic globalization, has been surging and sweeping the whole world. With the development of globalization, more and more global problems have appeared. Therefore, rising "global citizens" who have global awareness and are able to act have attracted the world's attention, and this is also the key to Global Citizenship Education. Looking around the world, Global Citizenship Education is just ascendant. Globalization brings people opportunities and benefits, but also results in the "global sharing" problems. These problems such as environmental pollution, transnational crime, terrorism, scientific and technological unemployment, lack of resources, poverty, disease and so on, have posed a serious threat to the survival and development of human beings. Practice has proved that it is far from enough to solve the above problems, relying solely on the strength of a country or an area. They require humans to objectively form a kind of logic of collective action, through cooperation, dialogue and consultation, to achieve effective and consistent in value and survival consciousness and other aspects, so as to gradually eliminate the problems through global governance. "Everyone is responsible for the rise and fall of the world", whereas now the "world" is no longer a narrow sense of the nation, but rise to the whole world or the "globe", the whole "Community with a Shared Future for Mankind". To achieve such a consensus, it is inevitable to put the Global Citizenship Education on the agenda of today's education.

\section{WhAT IS GLOBAL CITIZENSHIP EDUCATION}

First of all, the term "global citizen" or "citizen of the world" has been in existence for a long time. Since the enlightenment campaign, there have been a number of intellectuals with broad-minded and international perspectives who have surpassed the narrow vision and emotion of the country or nation. They call themselves "citizens of the world". Marx, in particular, even if displaced, was devoted to the liberation of the proletariat and the whole of mankind, working tirelessly for a lifetime. He was deported by the French government, the Belgian government, and the Prussia authorities; In December 1845, Marx declared his independence from Prussia, and then he did not gain any other nationality of other countries. Marx died in London on March 14, 1883. Before he passed away, Marx called himself a "citizen of the world". In fact, in the age of nation-state, the state and the outside world were usually blocked by obstacles. Under such circumstances, for a common "citizen", he was obviously far from the concept of "the citizen of the world". But now it is different. This is because today's human beings have entered the era of "globalization", and the vast world has become a "global village". The links between countries and regions are increasingly close, and different cultures and ideas are stirring each other. It can be said that everyone has become a "citizen of the world" to some extent. Even without going abroad, he can interconnect with the outside world to certain extent under the convenient traffic conditions and the ubiquitous Internet, and this communication will become more and more extensive and deeper with the progress of science and technology. Hence, "global citizen" or "citizen of the world" is the product of globalization, and will, in turn, react upon globalization in a larger and wider range.

There has been no accurate definition of Global Citizenship Education in the academic field, but this does not affect our understanding of the concept of it. Global citizenship refers to a sense of belonging to a broader community and common humanity. It emphasises political, economic, social and cultural interdependency and interconnectedness between the local, the 
national and the global [1]. Global citizenship education aims to be transformative, building the knowledge, skills, values and attitudes that learners need to be able to contribute to a more inclusive, just and peaceful world [2]. In general, global citizenship education can be understood as a special form of civic education. It can not only develop people's global consciousness, but also train people to use global awareness in practical activities. It involves students' active participation in the course study of solving the global social, political, economic, cultural, or environmental issues, as well as project practice.

\section{The OBJECTIVE AND CONTENT OF GLOBAL CitIZENSHIP EDUCATION}

In the report of the 19th National Congress of the Communist Party of China, Xi Jinping pointed out that, "The Communist Party of China strives for both the well-being of the Chinese people and human progress. To make new and greater contributions for mankind is our Party's abiding mission." He also stressed that, "We, the Chinese, are ready to work with the people of all other countries to build a community with a shared future for mankind and create a bright tomorrow for all of us." General secretary Xi Jinping's idea of "promoting the building of a community with a shared future for mankind" is an enrichment and development of Marxism under the new historical and contemporary conditions It has contributed Chinese wisdom and Chinese approaches to the global ecological harmony, the cause of international peace, the reform of the global governance system, and the establishment of a new order of global equity and justice. It has also put forward new goals and the fundamental direction for the contemporary Chinese national education, especially for the global citizenship education of the young generation. As a matter of fact, Marx and Engels have rich thoughts about "a community with a shared future for mankind". They believe, "only in the community can individuals get the means to develop their talents in an all-round way, that is to say, only in the community can there be personal freedom." Marx further put forward the idea of "real community". In Marx's view, the "real community" is opposed to the "false community". The "real community" is the union of the free men of the communist "world of universal harmony". And this union is an ideal society for everyone to achieve individual liberty and comprehensive development. Thus, no matter globalization or the "real community" which is also called "community of freeman" that composed of global citizens, its keynote is connected with the idea of "promoting the building of a community with a shared future for mankind". It is obvious that the idea of "promoting the building of a community with a shared future for mankind" has pointed out the direction, the goal and the vision for us to promote and expand the global citizenship education in the new era or the new historical conditions. Moreover, the global citizenship education has also been truly endowed with the right value orientation to adapt to the globalization process, as well as the broad vision and profound connotation.

As far as the current situation is concerned, there are many expressions about goals and contents of global citizenship education both at home and abroad. Due to cultural differences, the opinions of relevant experts and scholars are different from each other. However, in general, the corresponding consensus is reflected to a certain extent. The National Council for the Social Studies (US) made the following description of the goal of global citizenship education in 2001, "global citizenship education aims to cultivate children and teenagers with the necessary knowledge, attitudes, skills and sense of responsibility so that they can become eligible global citizens in the 21st Century" [3]. To sum up, the goal of global citizenship education can be understood as: let students get the following six major consciousnesses through education, and at the same time, complete the training of their related knowledge, attitudes, skills and sense of responsibility. The six consciousnesses are: values consciousness, intercultural consciousness, earth consciousness, system consciousness, science and technology consciousnes, as well as participation consciousness.

At present, there are more and more relevant introduction to the content of global citizen education. Among them, Iran scholar Mohsen introduced the content of global citizenship education from three aspects: knowledge, skills and value. Mohsen asserted that, "Educating global citizens is teaching those skills and attitudes that make them aware, active, critical and sociable citizens. Students need the knowledge, skill, and attitudes which enable them to have an active role in different areas as a member of the world community" [4]. Therefore, he drew the following table with the parameters of "knowledge development and understanding", "skills" and "values and attitudes". 
TABLE I.

THE CONTENTS OF GLOBAL CITIZENSHIP EDUCATION

KNOWLEDGE DEVELOPMENT AND
UNDERSTANDING
Social equality
Awareness of the destructive and
harmful factors for the environment
Awareness of international law
Awareness of the role of government in
establishing democracy
Awareness of the differences between
political institutions in different
countries
Awareness of the citizenship role in an
international scale
Awareness of the globalization and
interdependence

Awareness of the global aspect of the issues such as immigration, trade, consumer's rights, ... and fatal malaria

Awareness of different types of government in different countries and the major characteristics of their parliaments

\footnotetext{
Awareness of the different religious national and moral identities of different countries

Awareness of the influencing factors in sustainable development and peace
}

Dialogue and communicating ability

Logical and just decision making

Accountability, cooperation, and conflict

\section{VALUES AND ATTITUDES}

Thankfulness attitude towards cultural
heritage of other countries

Accepting and respecting pluralism in society

Respecting others' rights ability to challenge injustice and inequalities

Mutual understanding ability

Being interested in human rights

Concern for the environment safety

Sense of identity and self esteem

Participation and cooperation ability

Commitment to social justice and equality

Respect for people and things

Respect for traditions and culture of other countries

Tolerating opposing views

Respect for human beings

Ability to evaluate different global issues

Valuing and respecting diversity

Concern for his own and others' peace and welfare

Sense of patriotism

Law oriented attitude

\section{The CONCRETE PRACTICES OF GLOBAL CITIZENShIP EDUCATION}

The emergence of regional economic group and supranational political institutions (e.g., the European Union), as well as the progress of information and communication technologies, has attracted the attention of those governments and their relevant personage. They are also making efforts to increase their citizens' competitiveness in the global job market. As a result, all countries are scrambling to introduce global citizen education into the primary and secondary education. At the same time, global citizen education is being carried out orderly in non-governmental organizations, independent grassroots organizations, and other large educational institutions. These organizations or projects include: UNESCO, Oxfam, the International Alliance of Research Universities, and the Global Education First Initiative Plan.

The United Nations Educational Scientific and Cultural Organization (UNESCO) is indisputably the world's first international organization to promote and carry out global citizenship education. From the idea of the early "international understanding education", and then to the renamed "world citizenship education", and till today, the global citizenship education curriculum developing under the guiding of "Education 2030 Framework for Action", the UNESCO's practice of global citizenship education has gone through more than half a century. The sustainable development goals in the
UNESCO "Education 2030 Framework for Action" are described as follows: "The knowledge, skills, values and attitudes required by citizens to lead productive lives, make informed decisions and assume active roles locally and globally in facing and resolving global challenges can be acquired through education for sustainable development and global citizenship education, which includes peace and human rights education as well as intercultural education and education for international understanding".[5]

Oxfam is an international confederation of 20 organizations working together with partners and local communities in more than 90 countries. It is determined to change that world by mobilizing the power of people against poverty. Oxfam believes: "In a fast-changing and interdependent world, education can, and should, help young people to meet the challenges they will confront now and in the future". According to Oxfam, global citizen education can promote the understanding of multiculturalism, anti-racism and develop environmental education. Since the Curriculum for Global Citizenship was developed in 1997, it has been used by many schools. However, it is not set in stone. Teachers and young people might find that there are other areas of knowledge they would like to explore, other skills they need to acquire and other values they want to examine. In a changing world, they need to be flexible and thoughtful about how to educate for Global Citizenship [6]. 
The International Alliance of Research Universities (IARU), established in 2006, is a network of eleven international research-intensive universities from nine countries across the globe. We can take one of its project as an example of global citizenship education: IARU Global Summer Program. The Global Summer Program (GSP) is an exciting learning experience that connects students from IARU universities with their peers from around the world. GSP participants have the unique opportunity to come together to explore and discuss critical issues from a global perspective that requires multidisciplinary approaches. GSP is a chance to learn from a diverse and dynamic group of people coming together for the purpose of sharing knowledge, learning and getting new angles on research. It can teach students to think deeper, out of the box and show them how to integrate research across multiple disciplines. It enables people from different backgrounds but with the same aspirations, to open up their academic and personal horizons [7].

The United Nations Secretary-General launched the fiveyear Global Education First Initiative (GEFI) Plan in September 2012 to accelerate progress towards the Education for All goals and the education-related Millennium Development Goals. The Initiative aims to: Rally together a broad spectrum of actors for the final push to 2015; Put quality, relevant and transformative education at the heart of the social, political and development agendas; Generate additional and sufficient funding for education through sustained global advocacy efforts. The plan focuses on three prioritized areas: Put every child in school; Improve quality of learning; Foster global citizenship. The world faces global challenges that require global solutions. It is not enough for education to produce individuals who can read, write and count. Education must be transformative and bring shared values to life. It must cultivate an active care for the world and for those with whom we share it. Education must also be relevant in answering the big questions of the day. Technological solutions, political regulation or financial instruments alone cannot achieve sustainable development. It requires transforming the way people think and act. Education must fully assume its central role in helping people to forge more just, peaceful, tolerant and inclusive societies. It must give people the understanding, skills and values they need to cooperate in resolving the interconnected challenges of the 21st century [8].

\section{The ENLIGHTENMENT OF GLOBAL CITIZENShiP EDUCATION}

International exploration of the concept and practice of global citizenship education have provided much inspiration for Chinese colleges universities to promote global citizenship education. Based on the useful experience of foreign countries and from the specific national conditions of China, the following suggestions are made for Chinese colleges universities to actively promote global citizenship education:

Develop education goals that are both global and national. The goal of education is not only the starting point but also the destination of educational activities. The first thing to be noticed in carrying out global citizenship education in Chinese colleges and universities is that educational goals must be both global and national. Both of them are indispensable. The university stage is the choosing and positioning stage of young students' life. That is, college students are in the crucial period of establishing world outlook, outlook on life and values. Therefore, the importance of developing global citizenship education at this stage cannot be underestimated. Generally speaking the most prominent feature of the goal of global citizenship education is to cultivate global citizens with global awareness and international vision, and thus, it also demonstrates the global or cosmopolitan nature of global citizenship education. On the whole, the global nature of global citizenship education is reflected in knowledge, ability, values and attitudes, including: to understand the world's national, historical, cultural traditions, customs and other knowledge of world civilization; to understand the relevant knowledge of international law and international organizations; to have cross cultural communication skills; to have the ability to analyze global issues and have the ability of critical thinking; to have the pluralistic values of the "global community"... However, a global citizen is first and foremost a citizen of a country, and he must understand the history, culture, traditions and customs of its own country. One must identify with the cultural spirit of the nation and possess the cultural consciousness of the nation. Otherwise, he would not be qualified to talk about the global cultural identity.

Set up related courses of global citizenship education reasonably. Curriculum is the core of university education, and the media linking school and society. It is also an important way to implement global citizenship education. To carry out global citizenship education in Chinese colleges and universities, we can draw on the previous experience of developed countries and add some related courses in the curriculum setting system of the University. At present, a little part of the courses have infiltrated the idea of global citizen education in Chinese colleges and universities, such as the courses involve environmental protection, sustainable development, intercultural communication, etc. Nevertheless, developing global citizenship education and cultivating global citizens that meet the requirements of the times should set up a more professional and targeted global citizenship courses, so as to comply with the goal of global citizenship education, and effectively carry out the global citizenship education. In this respect, the Lehigh University (LU) has made a good demonstration. Lehigh University is one of the top private research institutions with a long history in the United States. In order to cultivate global citizens, the school not only initiated the global citizenship program, but also set up the corresponding courses and the required credits for the courses. For example, "Introduction to global citizenship" (3 credits), "Energy: origin, influence and choice" (3 credits), Cosmopolitanism and culture (4 credits), Citizen and city (2 credits), Global citizenship peak course (2-4 credits), etc. [9].

Further strengthen intercultural exchange and cooperation among colleges and universities around the world. In addition to developing global citizenship education courses, the most effective way to develop global citizenship education in Chinese colleges and universities is to enhance cross-cultural communication and cooperation in colleges and universities from different countries in the world. In this way, it can not only improve the international level of the university, but also 
serve as a practice of the global citizen education itself. There are many ways to intercultural communication, including organizing students to attend international academic conferences, participating in a series of conducted by international non-governmental organizations, and participating in international exchange programs. Take the Duke University as an example. Duke University is a worldrenowned research university, and is also recognized as one of the world's first class institutions of higher education. In order to promote the development of the school, Duke University released the "Duke University quality improvement program" in 2009. Its theme is "Global Duke: Enhancing Students' Capacity for World Citizenship ". The university planned to implement a series of new project activities in 2010, including the winter forum, global overseas term projects, global consulting projects, and so on [10].

Without any doubt, the reference does not mean to receive and copy the whole, but to learn critically and dialectically. For example, we can use the experience of the Lehigh University for reference. When we set up courses of global citizenship education, we can learn from its multi-layered curriculum system. Due to its diversified characteristics, we can categorize students into different grades and majors, and offer them targeted courses. Only in this way can students really acquire knowledge and improve their abilities from the courses, rather than just scratching the surface. In the meantime, it is also significant that we should pay attention to the goal of global citizenship education. No matter what kind of measures we will take, it must serve the "Global and National" principle. Only in this way can Chinese global citizenship education develop healthily and continuously.

\section{CONCLUSION}

With the development of economy, technology and social lives, China is playing an increasingly important role in the international arena. Facing the crisis and problems that mankind needs to solve together, and practicing global citizenship education, China must not be absent. The triumph of 19th National Congress of the Communist Party of China marks a new historical stage in China's reform and development. For China, this new historical stage means that the international status and world influence of contemporary China are rising. It also means that China will continue to make greater contributions to mankind. After learning from the practice of global citizenship education in the world, especially the practice in the developed countries, we should reexamine the present citizenship education in China profoundly and try to take practical measures. For example, to carry out global citizenship education in Chinese colleges and universities, we should pay attention to the following points: Training the national citizens' sense of identity to the basic spirit of Chinese culture is the prerequisite of the global citizenship education in China; While paying attention to the level and richness of the added courses related to global citizenship education, it must serve the goal of global citizenship education which has both global and national character; Strengthening cross-cultural exchanges and cooperation in colleges and universities so that global citizenship education can be fully implemented in this process. In conclusion, we must always maintain a clear mind, keep pace with the times and adapt to the needs of the times, and find a proper way to develop global citizenship education with Chinese characteristics.

Obviously, the promotion and implementation of global citizenship education, which embodies Chinese characteristics with high quality and high level, is not only the essential requirement of deepening the globalization process, but also the important condition for China to exert its own international influence. And it is also the basic premise for China to make a greater contribution to all humanity.

\section{REFERENCES}

[1] McDougall H. (2005). "From the Individual to the World: global citizenship in education, thought and practice." Doctoral dissertation, Indiana University.

[2] Carter, April. (2001). "The Political Theory of Global Citizenship." New York: Routledge.

[3] Haigh M. (2014). "From Internationalisation to Education for Global Citizenship: a Multi - Layered History." Higher Education Quarterly.

[4] Mohsen Farmahini Farahani. (2014). "The Role of Global Citizenship Education in World Peace and Security." Procedia - Social and Behavioral Sciences.

[5] Education 2030 Incheon Declaration and Framework for Action.

[6] Oxfam Development Education Programme. (2006). "Education for global citizenship: A guide for schools." Oxfam GB.

[7] "About IARU." http://www.iaruni.org/about/about-iaru.

[8] About the Global Education First Initiative.

[9] Official website of Lehigh University.

[10] Global Duke: Enhancing Students' Capacity for World Citizenship. 